\title{
Effects of Mutual Grafting on Photosynthetic Characteristics of two ecotypes of Solanum photeinocarpum under Cadmium Stress
}

\author{
Maolin Chen ${ }^{1, a}$, Cheng Chen ${ }^{1, b}$, Lei Liü ${ }^{2, c}$, Wei Jiang ${ }^{3, d}$ and Lijin Lin ${ }^{4, e^{*}}$ \\ ${ }^{1}$ College of Economics, Sichuan Agricultural University, Chengdu, Sichuan, China \\ ${ }^{2}$ Chengdu Academy of Agriculture and Forestry Sciences, Chengdu, Sichuan, China \\ ${ }^{3}$ College of Chemistry and Life Science, Chengdu Normal University, Chengdu, Sichuan, China \\ ${ }^{4}$ Institute of Pomology and Olericulture, Sichuan Agricultural University, Chengdu, Sichuan, China \\ a3208585092@qq.com, b8521153@qq.com, c20925133@qq.com, d1399945180@qq.com, \\ ellj800924@163.com
}

${ }^{*}$ Corresponding author. Maolin Chen, Cheng Chen and Lei Liu contributed equally to this work.

Keywords: Mutual grafting; Photosynthetic characteristic; Solanum photeinocarpum; Cd stress Abstract: A pot experiment was conducted to study the effects of mutual grafting on photosynthetic characteristics of two ecotypes of Solanum photeinocarpum under cadmium (Cd) stress. Four treatments were used in the experiment: ungrafted of farmland ecotype (F-CK), ungrafted of mining ecotype (F-CK), the farmland ecotype as scion grafted on the rootstocks of mining ecotype (F-Scion), the mining ecotype as scion grafted on the rootstocks of farmland ecotype (M-Scion). The results showed that mutual grafting of two ecotypes of $S$. photeinocarpum could enhance the net photosynthetic rate $(\mathrm{Pn})$, transpiration rate $(\mathrm{Tr})$, stomatal conductance $(\mathrm{Gs})$ and $\mathrm{CO}_{2}$ concentration of intercellular $(\mathrm{Ci})$ of scion of $S$. photeinocarpum. The result of light use efficiency (LUE) was the same as $\mathrm{Pn}$, but the mutual grafting decreased the vapor pressure deficit of leaf (VpdL) of $S$. photeinocarpum. F-scion decreased water use efficiency (WUE) compared with M-CK, but M-scion increased WUE compared with M-CK. Therefore, mutual grafting could use to enhance the photosynthetic ability of two ecotypes of $S$. photeinocarpum under Cd stress, which would help to improve the phytoremediation ability of two ecotypes of $S$. photeinocarpum.

\section{Introduction}

In the nature, due to differences in the ecological environment, the different ecotypes of plants format, and their morphology and physiology are completely different [1-2]. For hyperaccumulator plants, the cadmium $(\mathrm{Cd})$ accumulation in mining ecotype of Sedum alfredii Hance is much higher than that in non-mining ecotype [3]. The Cd contents in different areas of Solanum nigrum L. is also very different [4], and other scholars' studies have yielded similar results [5]. Solanum photeinocarpum is one of the wild vegetables, and also a potential Cd-hyperaccumulator plant [6]. Using the grafting can enhance the photosynthesis ability of S. photeinocarpum [7]. In the previous studies, the morphology and $\mathrm{Cd}$ accumulation of different ecotypes of $S$. photeinocarpum were quite difference. Compared with the farmland ecotype, the mining ecotype of $S$. photeinocarpum was short and lower biomass, but had more Cd contents in plant [8]. So, to further enhancing the phytoremediation of $S$. photeinocarpum, a pot experiment was conducted to study the effects of mutual grafting on photosynthetic characteristics of two ecotypes of $S$. photeinocarpum under $\mathrm{Cd}$ stress. The objectives of this study were to determine whether mutual grafting could enhance photosynthetic ability of two ecotypes of $S$. photeinocarpum under Cd stress.

\section{Materials and Methods}

Materials. The seeds of two ecotypes (mining ecotype and farmland ecotype) of S. photeinocarpum were collected from Tangjiashan lead-zinc mine and farmland of Ya'an campus farm of Sichuan Agricultural University in May, 2016, air-dried and stored at $4{ }^{\circ} \mathrm{C}$ respectively. The Tangjiashan 
lead-zinc mine $\left(29^{\circ} 24^{\prime} \mathrm{N}, 102^{\circ} 38^{\prime}\right.$ E) locates in Hanyuan County, Sichuan Province, China, with an typical dry-hot valley climate. The farm of Sichuan Agricultural University (29 $\left.59^{\prime} \mathrm{N}, 102^{\circ} 59^{\prime} \mathrm{E}\right)$ locates in Yucheng County, Sichuan Province, China, with an humid subtropical monsoon climate.

Grafting. The seeds of two ecotypes of S. photeinocarpum were sown in the farmland of the Chengdu campus in June, 2016. When the $S$. photeinocarpum seedlings reached a height of $\sim 10 \mathrm{~cm}$ (eight expanded euphyllas, rapid growth stage), the grafting was conducted. The grafting method was cleft grafting bound with 1-cm-wide plastic film. All of the leaves of the rootstocks remained. There were four treatments in the experiment. (1) Ungrafted of farmland ecotype (F-CK). (2) Ungrafted of mining ecotype (F-CK). (3) The farmland ecotype as scion grafted on the rootstocks of mining ecotype (F-Scion). (4) The mining ecotype as scion grafted on the rootstocks of farmland ecotype (M-Scion). When the grafting was completed, the soil moisture content was maintained at $80 \%$ of field capacity, and all of the seedlings were covered with transparent plastic film and a shade net. After $10 \mathrm{~d}$, the transparent plastic film, the shade net and the plastic binding films were removed.

Experimental Design. The experiment was conducted at the Chengdu campus from June to August 2016. The soil samples were air-dried and passed through a 5-mm mesh in June 2016, and then $3.0 \mathrm{~kg}$ of soil was weighed into each polyethylene pot $(15 \mathrm{~cm}$ tall, $18 \mathrm{~cm}$ diameter). Cd was added to make a final soil $\mathrm{Cd}$ concentration of $10 \mathrm{mg} \cdot \mathrm{kg}^{-1}$ with a saturated heavy metal solution in the form of $\mathrm{CdCl}_{2} \cdot 2.5 \mathrm{H}_{2} \mathrm{O}$. The soils were mixed immediately and again after 4 weeks, during which soil moisture was kept at $80 \%$. Four uniformly prepared $S$. photeinocarpum seedlings of each treatment were transplanted into each pot in July 2016. Each treatment was repeated three times with a 10-cm spacing between pots. The soil moisture content was maintained at $80 \%$ of field capacity until the plants were harvested. After S. photeinocarpum matured (30 d of cultivation at the fully blooming stage), the photosynthesis of each plant was determined by using LI-6400 portable photosynthesis meter (LI-COR Inc., USA). The photosynthetic parameters of the photosynthesis meter were manual control $\mathrm{CO}_{2}$ concentration $400 \mu \mathrm{mol} \cdot \mathrm{mol}^{-1}$, temperature $25^{\circ} \mathrm{C}$, light intensity $1000 \mu \mathrm{mol} \cdot \mathrm{m}^{-2} \mathrm{~s}^{-1}$. The determination of photosynthetic parameters were net photosynthetic rate $(\mathrm{Pn})$, transpiration rate $(\mathrm{Tr})$, stomatal conductance (Gs) and $\mathrm{CO}_{2}$ concentration of intercellular $(\mathrm{Ci})$, and each treatment was repeated three times. Water use efficiency $(\mathrm{WUE})=$ net photosynthetic rate $(\mathrm{Pn}) /$ transpiration rate (Tr), Light use efficiency (LUE) = net photosynthetic rate (Pn) / light intensity [9].

\section{Results and Discussion}

Net Photosynthetic Rate (Pn). Compared with F-CK, the Pn of M-CK was lower than F-CK (Table 1 ), indicating that farmland ecotype of $S$. photeinocarpum had higher photosynthesis than mining ecotype. The grafting enhanced the Pn of F-scion by $14.91 \%(p<0.05)$ compared with F-CK under $\mathrm{Cd}$ stress, and enhanced the Pn of M-scion by $17.89 \%(p<0.05)$ compared with M-CK. So, the grafting could enhance the photosynthesis ability of $S$. photeinocarpum under Cd stress, and the enhancement degree of farmland ecotype was higher than mining ecotype.

Transpiration Rate (Tr). The same as the Pn, the Tr of farmland ecotype of S. photeinocarpum was also higher than mining ecotype (Table 1). The grafting increased the Tr of two ecotype of $S$. photeinocarpum compared with their control respectively. The grafting increased the Tr of F-scion by $73.76 \%(p<0.05)$ compared with F-CK, and increased the Tr of M-scion by $13.04 \%(p<0.05)$ compared with M-CK. So, the Tr enhancement degree of farmland ecotype was higher than mining ecotype.

Stomatal Conductance (Gs). After grafting, the Gs of two ecotypes of S. photeinocarpum increased (Table 1), which was benefit to the Pn. The Gs of S. photeinocarpum was ranked as: F-scion > F-CK > M-scion > M-CK. Compared with F-CK, F-scion decreased the Gs of $S$. photeinocarpum by $85.82 \%$ ( $p<0.05$ ). Compared with M-CK, M-scion decreased the Gs of $S$. photeinocarpum by $15.04 \%(p<0.05)$. So, the Gs enhancement degree of farmland ecotype was higher than mining ecotype. 
$\mathrm{CO}_{2}$ Concentration of Intercellular (Ci). The same as Gs, after grafting, Ci of two ecotype of $S$. photeinocarpum increased (Table 1). The $\mathrm{Ci}$ of $\mathrm{S}$. photeinocarpum was ranked as: F-scion > F-CK > M-scion > M-CK. Compared with F-CK, F-scion decreased the Ci of S. photeinocarpum by $11.09 \%$ $(p<0.05)$, and M-scion decreased the Ci of S. photeinocarpum by $2.48 \%(p<0.05)$ compared with $\mathrm{M}-\mathrm{CK}$.

Table $1 \mathrm{Pn}, \mathrm{Tr}, \mathrm{Gs}$ and $\mathrm{Ci}$ of mutual grafted S. photeinocarpum

\begin{tabular}{|c|c|c|c|c|}
\hline Treatments & $\begin{array}{c}\mathrm{Pn} \\
\left(\mu \mathrm{mol} \mathrm{CO} 2 \cdot \mathrm{m}^{-2} \cdot \mathrm{s}^{-1}\right)\end{array}$ & $\begin{array}{c}\mathrm{Tr} \\
\left(\mathrm{mol} \mathrm{H} \mathrm{O}_{2} \mathrm{O} \cdot \mathrm{m}^{-2} \cdot \mathrm{s}^{-1}\right)\end{array}$ & $\begin{array}{c}\mathrm{Gs} \\
\left(\mathrm{mol} \mathrm{H} \mathrm{H}_{2} \mathrm{O} \cdot \mathrm{m}^{-2} \cdot \mathrm{s}^{-1}\right)\end{array}$ & $\begin{array}{c}\mathrm{Ci} \\
\left(\mathrm{mmol} \mathrm{CO}_{2} \cdot \mathrm{mol}^{-1}\right)\end{array}$ \\
\hline $\mathrm{F}-\mathrm{CK}$ & $5.03 \pm 0.21 b$ & $0.972 \pm 0.023 b$ & $0.0677 \pm 0.0031 b$ & $268.65 \pm 5.56 b$ \\
\hline F-scion & $5.78 \pm 0.26 \mathrm{a}$ & $1.689 \pm 0.069 \mathrm{a}$ & $0.1258 \pm 0.0053 a$ & $298.44 \pm 3.15 a$ \\
\hline $\mathrm{M}-\mathrm{CK}$ & $2.85 \pm 0.20 \mathrm{~d}$ & $0.629 \pm 0.016 \mathrm{~d}$ & $0.0552 \pm 0.0033 c$ & $265.15 \pm 7.52 b$ \\
\hline M-scion & $3.36 \pm 0.02 \mathrm{c}$ & $0.711 \pm 0.013 \mathrm{c}$ & $0.0635 \pm 0.0016 b$ & $271.73 \pm 5.89 b$ \\
\hline
\end{tabular}

Values are means of three replicate pots. Different lowercase letters indicate significant differences based on one-way analysis of variance in SPSS 13.0 followed by the least significant difference test $(p<0.05)$. F-CK = ungrafted of farmland ecotype, F-CK = ungrafted of mining ecotype, F-Scion $=$ the farmland ecotype as scion grafted on the rootstocks of mining ecotype, M-Scion = the mining ecotype as scion grafted on the rootstocks of farmland ecotype.

Water Use Efficiency (WUE). The Fig. 1 shows that WUE of two ecotypes of S. photeinocarpum effected by grafting treatment under Cd stress. Compared with M-CK, F-scion decreased WUE by $33.87 \%(p<0.05)$, but M-scion increased WUE by $33.87 \%(p<0.05)$ compared with M-CK.

Light Use Efficiency (LUE). The same as the Pn, the grafting increased LUE of two ecotypes of $S$. photeinocarpum under Cd stress (Fig. 2). The LUE of S. photeinocarpum was ranked as: F-scion > F-CK > M-scion > M-CK. F-scion increased LUE of $S$. photeinocarpum by $14.91 \%(p<0.05)$ compared with F-CK, and M-scion increased LUE by $17.89 \%(p<0.05)$ compared with M-CK.

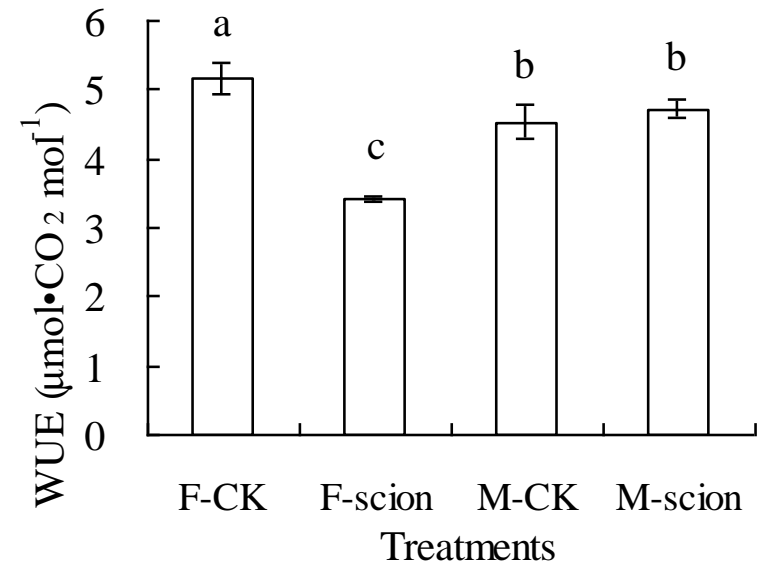

Fig. 1 WUE of mutual grafted $S$. photeinocarpum. Values are means of three replicate pots. Different lowercase letters indicate significant differences based on one-way analysis of variance in SPSS 13.0 followed by the least significant difference test $(p<0.05)$. F-CK $=$ ungrafted of farmland ecotype, $\mathrm{F}-\mathrm{CK}=$ ungrafted of mining ecotype, F-Scion $=$ the farmland ecotype as scion grafted on the rootstocks of mining ecotype, $\mathrm{M}$-Scion = the mining ecotype as scion grafted on the rootstocks of farmland ecotype.

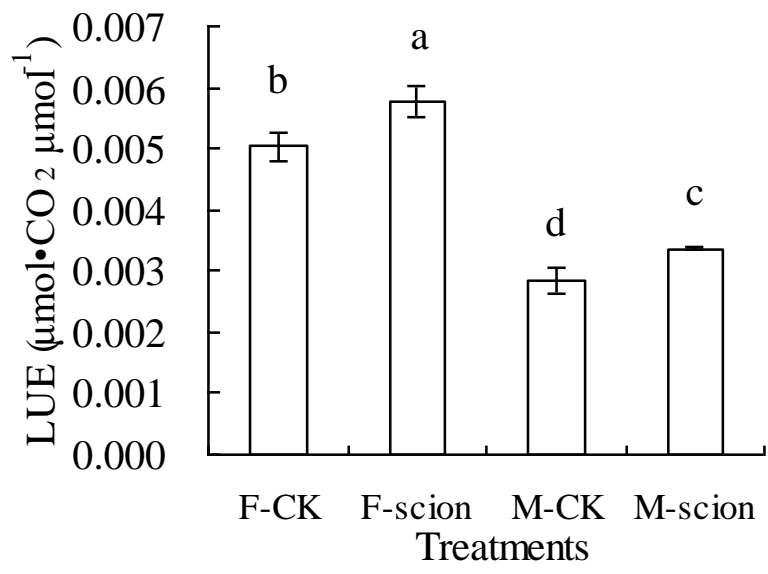

Fig. 2 LUE of mutual grafted $S$. photeinocarpum. Values are means of three replicate pots. Different lowercase letters indicate significant differences based on one-way analysis of variance in SPSS 13.0 followed by the least significant difference test $(p<0.05)$. F-CK $=$ ungrafted of farmland ecotype, F-CK = ungrafted of mining ecotype, F-Scion $=$ the farmland ecotype as scion grafted on the rootstocks of mining ecotype, M-Scion = the mining ecotype as scion grafted on the rootstocks of farmland ecotype. 
Vapor Pressure Deficit of Leaf (VpdL). The Fig. 3 shows that the VpdL of two ecotypes of $S$. photeinocarpum effected by grafting treatment under Cd stress. The VpdL of farmland ecotype of S. photeinocarpum had lower VpdL than mining ecotype. Compared with M-CK, F-scion decreased the VpdL by $4.30 \%(p<0.05)$, and M-scion increased the VpdL by $12.53 \%(p<0.05)$ compared with M-CK.

\section{Conclusions}

Mutual grafting of two ecotypes of $S$. photeinocarpum could enhance the $\mathrm{Pn}, \mathrm{Tr}$, Gs and $\mathrm{Ci}$ of scion of $S$. photeinocarpum. The result of LUE was the same as Pn, but the mutual grafting decreased the VpdL of S. photeinocarpum. F-scion decreased WUE compared with M-CK, but M-scion increased WUE compared with M-CK. Therefore, mutual grafting could use to enhance the photosynthetic ability of two ecotypes of $S$. photeinocarpum under $\mathrm{Cd}$ stress, which would help to improve the phytoremediation ability of two ecotypes of $S$. photeinocarpum.

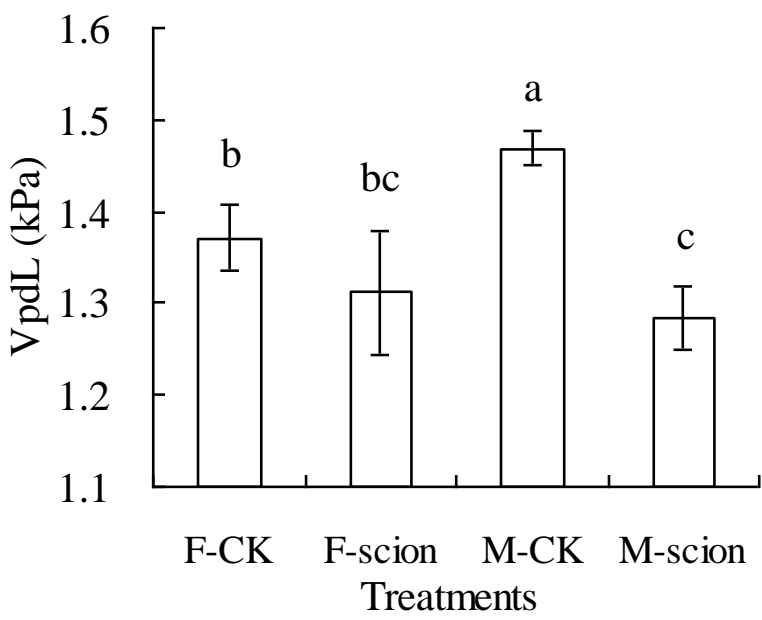

Fig. 3 VpdL of mutual grafted $S$. photeinocarpum. Values are means of three replicate pots. Different lowercase letters indicate significant differences based on one-way analysis of variance in SPSS 13.0 followed by the least significant difference test $(p<0.05)$. F-CK $=$ ungrafted of farmland ecotype, F-CK = ungrafted of mining ecotype, $\mathrm{F}-\mathrm{Scion}=$ the farmland ecotype as scion grafted on the rootstocks of mining ecotype, $\mathrm{M}$-Scion = the mining ecotype as scion grafted on the rootstocks of farmland ecotype.

\section{Acknowledgements}

This work was financially supported by the 2016 Innovation Training Program of University Student (201610626032) and the Application Infrastructure Project of Science and Technology Department of Sichuan Province (2016JY0258).

\section{References}

[1] J.H. Zhu, L.M. Pan, X.Q. Qin, H.X. Peng, Y. Wang and Z.H. Han: Journal of Plant Genetic Resources Vol. 14 (2013), p. 65.

[2] P.D. Tai, S.H. Guo, Y.F. Song, T.H. Sun and P.J. Li: Chinese Journal of Applied Ecology Vol. 11 (2000), p. 53.

[3] X.X. Long, Y.H. Wang and H.Y. Liu: Journal of Plant Ecology Vol. 32 (2008), p. 168.

[4] S.H. Wei, G. Clark, A.I. Doronila, J. Jin and A.C. Monsant: International Journal of Phytoremediation Vol. 15 (2013), p. 199.

[5] L. Lin, M. Liao, L. Mei, J. Cheng, J. Liu, L. Luo and Y. Liu: Environmental Progress \& Sustainable Energy Vol. 33 (2014), p. 1251.

[6] X.F. Zhang, H.P. Xia, Z.A. Li, P. Zhuang and B. Gao: Journal of Hazardous Materials Vol. 189 (2011), p. 414.

[7] F. Tang, L. Lin and M. Liao: International Conference on Advances in Energy and Environmental Science (2015), p. 1254.

[8] J. Wang, L. Jin, L. Luo, M. Liao, X. Lv, Z. Wang, D. Liang and H. Xia: Environmental Monitoring and Assessment Vol. 188 (2016), p. 82. 
[9] X.J. Jiang, H. Wang, W. Peng, Y.X. Yang, X.M. Zhu and L.J. Lin: Shanxi Journal of Agricultural Sciences Vol. 54 (2008), p. 56. 